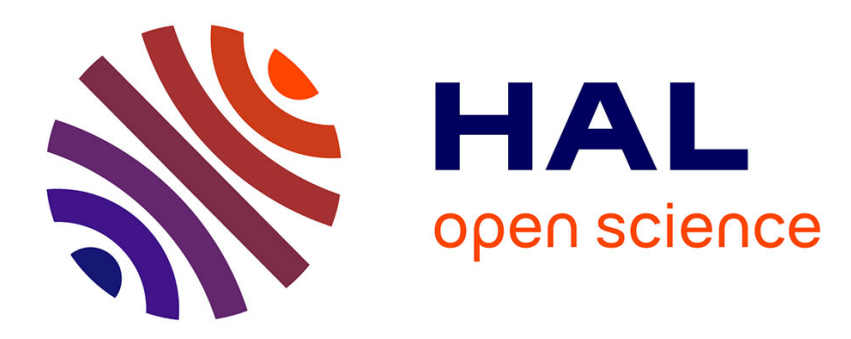

\title{
Pericyte ontogeny: the use of chimeras to track a cell lineage of diverse germ line origins
}

\author{
Heather C. Etchevers
}

\section{To cite this version:}

Heather C. Etchevers. Pericyte ontogeny: the use of chimeras to track a cell lineage of diverse germ line origins. 2017. hal-01586419

\section{HAL Id: hal-01586419 https://hal-amu.archives-ouvertes.fr/hal-01586419}

Preprint submitted on 12 Sep 2017

HAL is a multi-disciplinary open access archive for the deposit and dissemination of scientific research documents, whether they are published or not. The documents may come from teaching and research institutions in France or abroad, or from public or private research centers.
L'archive ouverte pluridisciplinaire HAL, est destinée au dépôt et à la diffusion de documents scientifiques de niveau recherche, publiés ou non, émanant des établissements d'enseignement et de recherche français ou étrangers, des laboratoires publics ou privés. 


\title{
Pericyte ontogeny: the use of chimeras to track a cell lineage of diverse germ line origins
}

\author{
Heather C. Etchevers \\ Aix Marseille Univ, INSERM, UMR_S910, GMGF, Marseille, France
}

November 2016

The goal of lineage tracing is to understand body formation over time by discovering which cells are the progeny of a specific, identified, ancestral progenitor. Subsidiary questions include unequivocal identification of what they have become, how many descendants develop, whether they live or die, and where they are located in the tissue or body at the end of the window examined. A classical approach in experimental embryology, lineage tracing continues to be used in developmental biology, stem cell and cancer research, wherever cellular potential and behavior need to be studied in multiple dimensions, of which one is time. Each technical approach has its advantages and drawbacks [1]. This brief review, with some previously unpublished data, will concentrate non-exclusively on the use of interspecies chimeras to explore the origins of perivascular (or mural) cells, of which those adjacent to the vascular endothelium are termed pericytes for this purpose. These studies laid the groundwork for our understanding that pericytes derive from progenitor mesenchymal pools of multiple origins in the vertebrate embryo, some of which persist into adulthood. The results obtained through xenografting complement and abut those obtained through genetic lineage tracing techniques within a given species.

\section{Brief history of the mysterious pericyte}

The word "pericyte" carries its own uncertain definition - by its position, rather than by its function. Careful observations by Rouget and drawn using a camera lucida in 1873, showed highly ramified cells, which he considered likely to be contractile smooth muscle cells (SMC), apposed tightly to the hyaloid microvasculature of the frog and the rabbit [2].

Capillaries, apparently the simplest blood vessels, are not functionally identical around the body. What is in common is the unit of the endothelial cell, in direct contact with the circulating blood and in tight contact with its lateral neighbor. However, even endothelial cells can be differentiated molecularly and phenotypically based on their position in new sprouts, or in lymphatic beds. Most capillaries are associated with some form of pericyte, a multipotent contractile cell type on the immediate abluminal surface of the endothelial cells. These are responsible for the secretion of a tissue-specific basal lamina [3] and may be closely apposed or not [4]. Depending on vessel type, there may then be one or more concentric layers of SMC, all encased by outer connective cells including fibroblasts, which maintain the position of the blood vessel within the tissue or cavity.

The term pericyte has expanded over time to encompass the description of any resident periendothelial cell, though it tends to be applied most to microvessels. There are both molecular and phenotypic 
features that are either distinct to, or in common between, the following cell types: brain capillary pericytes, arterial, venous or lymphatic periendothelial SMC, kidney podocytes, coronary vascular pericytes, liver stellate cells, myofibroblasts, bone marrow stroma, dental pulp stem cells and even a subpopulation of macrophages $[5,6]$.

Many of the specific cell types listed above appear to retain mesenchymal multipotency into adulthood in multiple species, further confounding terminology. It is therefore essential to define the cell type under study with both molecular markers and in vivo position in tissue relative to vascular endothelium and, optimally, its basal lamina [7]; short of these conditions, it is important to keep in mind that all markers used to date are typical of, but never restricted to, a given pericytic population $[8,9]$. For example, the large transmembrane glycoprotein encoded by the CSPG4 (chondroitin sulfate proteoglycan 4) gene, also known as NG2 (for nerve/glia antigen 2), is expressed by many multipotent cell types, such as mesenchymal, keratinocyte and radial glia stem cells, in addition to pericytes.

\section{An adaptable tool: xenografting}

A major fate-mapping technique used in experimental embryology from the last third of the $20^{\text {th }}$ century on, has been the construction of quail-chick chimeras. This approach exploits species differences in nuclear structure to permanently mark cells grafted from a donor to a host embryo [10], and has since been adapted to highlight immunological differences with species-specific antibodies [11]. The concept has taken many forms over the years. For example, mouse-chick and duck-chick chimeras have also been constructed, to study aspects of tooth or beak shape development and take advantage of introduced genetic modifications or species-specific attributes $[12,13]$. Transfected quail donors have also made it possible to combine persistent fate-mapping with localized in vivo responses to changes in gene expression [14].

The endothelial cell lineage differentiates itself from other future mesodermal progeny at a very early time point, when the future head is barely distinguished by an anterior transverse buckling in the germ layers and gastrulation is still underway. The tyrosine kinase-linked receptor to the major bioactive form of vascular endothelium growth factor (VEGFA), Vegfr2, is already expressed then in a subset of cephalic mesoderm that subsequently differentiate into endothelial cells [15]. VEGF is essential to early vascular development and endothelial survival, and is secreted by cell, including pericytes, contacting sprouting neovessels under both normal and pathological conditions [16-18]. Xenografts of mesodermal mesenchyme lateral to the future brain at times before neural crest migration participate in both striated muscles and the endothelium of all cephalic blood vessels [19, 20]. Vegfr2-expressing precursors coalesce and cavitate to create a primary capillary network. Thereafter, new blood vessels sprout from pre-existing vessels. The growth process is known as angiogenesis and occurs throughout life and the body. In vertebrates, such labile sprouts are stabilized by pericytic contact and molecular cross-talk that appears to be evolutionarily conserved $[16,18,21]$.

The development of antibodies against species-specific epitopes present on vascular endothelium, such as MB1/QH1 for the quail, which is not present in chicken endothelium [22, 23], prefigured the development of multiple conditional yet indelible fate-mapping techniques to trace the origins of 
endothelial cells from various intra- and extra-embryonic mesodermal sources. Confirmation of the mesodermal origins and further molecular properties of the vascular endothelium have been examined by fate-mapping in xenografting experiments [24, 25]. In the 2000s, Cre-lox [26]and Tol2 [27, 28] technologies allowed localized, timed recombination and subsequent expression of lineage tracers such as beta-galactosidase or fluorescent proteins, as well as functional manipulation of other genes' expression in specific populations. The Tie2-driven Cre recombinase has been particularly useful in following the vascular endothelial lineage in the mouse $[29,30]$ and validating the evolutionary conservation of the embryonic origins of the endothelium, but many other early and specific markers, such as Vegfr2-driven fluorescent markers, are also used for lineage tracing in multiple model species like zebrafish [31].

As VEGF, BMP and related signaling pathways have been shown to be critical for the establishment of vascular identity and function in other parts of the body [29,32], mediation by perivascular cells of signals between the surrounding tissue and the endothelium seems to be the rule and not the exception, no matter the embryological origin of the pericyte [33]. Because the potential for conferring these tissuespecific properties are at least in part a function of their origin, the results of pericytic lineage tracing remain relevant for understanding the causes of, and proposing adapted therapies for, vascular tumors and malformations and inappropriate angiogenesis.

\section{Multiple origins of pericytes}

\section{Neural crest}

Neural crest cells (NCC) detach from the left and right boundaries between the ectoderm and the neural plate, as the latter rolls up into a tube which will give rise to the central nervous system. Fate maps using avian embryo chimeras have shown that these NCC migrate into and through the perineural mesodermal mesenchyme until they both mingle with it and colonize the appropriate distal targets, where they differentiate into the peripheral nervous system, certain types of endocrine cells, and all extraretinal pigment cells [reviewed in 11]. Cephalic NCC also engender many tissues that in the body are derived from the mesoderm, with the notable exception of vascular endothelium, derivatives grouped under the heading of the "mesectoderm". These include the connective components of all head and neck glands, facial muscles and tendons. The dermis and adipose tissue overlying the jawed facial skeleton and brain case, the bones of that part of the skull; the meninges, including the vascular pia mater, underlying it are also of neural crest origin, as shown by lineage-tracing techniques in the avian embryo and later validated in other vertebrates [35-43].

Normally, NCC and VEGFR2-expressing mesenchyme surround the forebrain from the dorsal and ventral sides, respectively. Where they meet, they combine to form a leptomeningeal vascular plexus by the second day of incubation in the chick, although capillary penetration of the forebrain only occurs during the fifth day. In embryos experimentally deprived of rostral NCC, forebrain apoptosis occurs on the second and third days of incubation, such that the prospective forebrain tissue is not even present on the fifth day [44]. The experimental phenotype is due to a survival effect of mesenchyme of NCC origin on the early forebrain neuroepithelium within the pia mater, not compensated by unstabilized vascular endothelial precursors alone [45]. Much but not all of the NCC-derived perivascular mesenchyme in this 
location, both on the surface or intraparenchymally, ultimately expresses alpha-smooth muscle actin (aSMA). The migrating NCC normally counter environmental signals of the bone morphogenetic protein (BMP) and Wnt families and stimulate VEGF signaling [reviewed in 26] by producing multiple members of

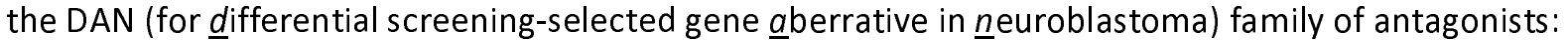
Gremlin (Grem), Dickkopf (Dkk1) and Cerberus (Cer1) [47]. Combinations of both quail-chick chimeras and molecular biology have demonstrated that the anteroposterior level of NCC origin determines its potential to enable forebrain survival and growth [48], and that only NCC with mesectodermal potential normally differentiates into pericytes and SMC.

The first indications of the unique role of NCC in cephalic blood vessels came from fate-mapping experiments using radioactive isotopes, retroviral infection or xenografting to show their constitution of the branchial arch mesenchyme and subsequent incorporation into the muscular walls of the corresponding large arteries [36, 49, 50]. NCC derived from the posterior rhombencephalon were shown to contribute all components of the proximal large arteries to the heart, with the exception of the endothelium. Subsequently, the functional role of NCC of this origin was noted in the septation of the pulmonary trunk from the aorta [51,52]. NCC are equally important to the smooth muscle wall of the posterior aortic arch arteries in mammals [26] and integrate into the walls of the cardinal veins [50,53]. NCC were shown with quail-chick chimeras to provide two distinct types of cells in the tunica media of large elastic arteries derived from the aortic arches, some non-SMC adventia, and an early periendothelial layer of NCC not organized in lamellar layers, and only sometimes expressing aSMA [54].

The cellular resolution afforded by interspecies chimeras enabled discovery of the origin and extent of a subpopulation pericytes in the multipotent cephalic NCC. Isotopic xenografts of small fragments of neural folds from brain levels corresponding to the future diencephalon and mesencephalon of quail donors resulted in abundant graft-derived NCC within the forebrain meninges of the chicken hosts, with a sharp border at the forebrain-midbrain boundary [53]. Quail cells, adjacent to endothelial capillary walls within the parenchyma and the leptomeninges, were co-immunostained with aSMA after a few days' maturation and determined to be pericytes. The vascular media of veins and sinuses were only a grafted cell or two thick, confirming independent work also using quail-chick chimeras [50]. SMC and outer mural connective tissue cells of graft origin were organized in cell-dense layers in the distal portions of the major cephalic arteries; most of these in cross-section were concentric and interspersed with eosinophilic elastin. Histological differences in elastin organization between the part of the aorta surrounded by SM of NCC versus mesodermal origin have also been noted by others [50], a SM heterogeneity much later borne out by functional studies of ductus arteriosus closure at birth in mice as described below [55].

Grafts of neural folds of the anterior rhombencephalon gave rise to all but the endothelial cells of the proximal segments of the arteries irrigating face and forebrain, as well as the distal internal carotid arteries. Median rhombencephalic neural folds contributed cells to the carotid arteries and cardinal veins, while posterior rhombencephalic NCC tended to incorporate into proximal segments of the carotid arteries, the aortic and pulmonary trunks and the conotruncus and semilunar valves of the heart itself, confirming reports by others $[53,56]$. Thus, the original anteroposterior origin of a cell within the neural folds corresponds to its final distoproximal distribution in a defined subset of cephalic blood 
vessels. This subset, designated the "branchial vascular sector", is a distinct circuit of blood vessels originating in the ventral aorta and aortic arches, ramifying into circumscribed capillary plexuses, and terminating in their venous return to the heart. These vessels irrigate the forebrain, neck, face and jaws, and in what appears to be a species-dependent pattern, anastomose with the evolutionarily more ancient vascular network in the head [53].

Pdfgrb appears to play an evolutionarily conserved role in pericyte biology in microvessels, since its promoter driving a fluorescent marker has enabled lineage tracing and live imaging of vascular mural cells within the elegant zebrafish model [57]. In order to observe the dynamics of pericyte-EC interactions, EC can be simultaneously traced with a distinct fluorescent reporter [58]. It is theoretically possible to make chimeras by transplanting cells from labeled donors into unlabeled wild-type hosts, particularly between blastula and gastrula or shield stages, where detailed fate maps are available. Chimeras can be a helpful tool for dissecting questions related to cell autonomous or non-autonomous effects of endogenous or exogenous signaling molecules on specific cell lineages, in combination with genetic gain-or-loss of function. To date, however, this labor-intensive strategy has been eschewed in favor of genetic combinations of lineage-specific labels with respect to studying teleost pericytes. This has been fruitful in confirming that the evolutionarily more recent brain and face indeed have neural crest-derived pericytes, while the rest of the body has mesoderm-derived pericytes, as shown by the reporters driven by the transcription factor genes Sox 10 and $T b \times 6$, respectively [57].

\section{Mesoderm}

A second vascular division can be distinguished in the head by virtue of its vessels not belonging to the branchial sector. Like in the rest of the body, its component arteries and veins share the property of being entirely constructed from the embryonic mesoderm. The cephalic mesoderm, although mesenchymal, is analogous to the axial and paraxial mesoderm of the body. In mature vertebrates, vessels branching rostrally from the aorta irrigate the dorsal head, including the midbrain, cerebellum and hindbrain. This vascular domain contacts the branchial sector at the circle of Willis, a large anastomosis between the bifurcation of the basilar artery and the cerebral arteries, branches of the internal carotids. This polygon surrounds the optic nerves and ventral diencephalon, reflecting the transition (at least in birds) within the meninges from an entirely mesoderm-derived region, the midbrain, to a composite mesoderm/NCC-derived region, the forebrain [53].

\section{Epicardium}

At the level of the heart, there is another vascular interface of neural crest-derived pericytes and SMC with their mesoderm-derived counterparts. The epicardium is a thin layer of specialized mesothelium that spreads from cells clustered on the coelomic surface of the right sinus venosus over the dorsal wall of the heart tube and toward the outflow tract during cardiac morphogenesis. A replication-defective adenovirus carrying the $L a C Z$ gene driven by a strong promoter, was used to follow the fate of a subset of either chicken proepicardium directly infected in ovo [59] or cultured quail epicardial cells or whole quail proepicardial primordia grafted into chick hosts $[56,60]$. In all cases, cells underwent an epithelialmesenchymal transition in order to leave the epicardial layer and integrate into the tunica media of both coronary arteries and veins. In addition, this epicardially derived mesenchyme also generated interstitial fibroblasts amongst the myocardium, indicating that this alternate source of pericytes and smooth 
muscle retains the capacity to give rise to non-vascular connective tissue, like its neural crest counterpart in the head. Some of the endothelial cells of the coronary vasculature were also graft-derived in independent studies $[56,59]$, indicating that either it is difficult to entirely remove endothelial components from grafted tissues (a potential pitfall for chimera approaches), or that within the mesoderm, contrary to the neural crest, endothelial cells and vascular pericytes share a common lineage. Certainly, pericytes and coronary artery SMC do, and fate-mapping in mice demonstrated that the first is a potential resident progenitor pool for the second, if it is possible to remobilize them pharmacologically [61].

\section{Mesothelium}

The part of the lateral plate mesoderm that is closest to the endoderm and its signals is the splanchnic mesoderm. Within this original two-dimensional epithelium, flanking the axis, are fields corresponding to distinct populations of prospective mesenchyme. In gastrulae, the anteriormost zone of embryonic "lateral" mesoderm beyond the future head will integrate into the liver, followed by the inverted Ushaped first heart field overlying the anterior intestinal portal [62], which will give rise to the left ventricle. This zone is succeeded in posterior order by the splanchnic mesoderm of the future second heart field (SHF), which follows the same shape slightly more median. At the posterior ends of the $U$, beyond the cells that will integrate into arterial pole myocardium [63], only the right primordium is maintained of initially bilateral prospective proepicardial fields, at least in amniotes. Chicken chimeras hosting grafts of vital dye-labelled lateral plate mesoderm subpopulations demonstrated that medial somatic mesoderm (in contact with the ectoderm, dorsal to the right sinus venosus) also contributes to the proepicardium [64]. All of these zones are capable of generating vascular SMC and fibroblasts, while only the posterior SHF [65] and epicardium make unambiguous pericytic contributions.

Further posterior, the splanchnic mesoderm gives rise to the WT1-expressing mesothelial layer covering all coelomic visceral organs - particularly the liver and digestive tract, but also the kidneys and gonads. This mesothelium contributes mesenchymal cells expressing aSMA and desmin, clearly SMC within arteries and veins but on smaller microvessels also, to the invasive vasculature of the entire developing gut [66].

\section{Sclerotome}

In counterpart, grafts of the presomitic mesoderm from quail to chick hosts have demonstrated that not only endothelial cells but also all the pericytes and vascular SMC of the limbs and trunk are derived from this paraxial population [67]. The lack of contribution to vascular SMC of the viscera was also noted in this work, indirectly confirming its origin from the splanchnic mesoderm. Furthermore, it is the part of the paraxial mesoderm in contact with the endoderm, which after first epithelialization into the somites, later becomes mesenchymal, that is the source of these outer body wall pericytes and vascular SMC. The pericytes were embedded in a laminin-rich basal lamina, and within the aortic wall, came from the Foxc2-expressing sclerotome. Interestingly, while Pdgfrb-positive grafted cells were numerous within the aortic SMC, the periendothelial cells most positive for aSMA did not express as much (or any) Pdgfrb as the more peripheral layers of the tunica media [67]. Further work showed that these sclerotomal smooth muscle cells had been preceded by a temporary contribution from the splanchnic mesoderm [68]. 
One might therefore predict that quail-chick chimeras of the ventral intermediate mesoderm, between paraxial and lateral plate populations, may also demonstrate pericytic and smooth muscle potential, perhaps for the specialized kidney pericytes known as podocytes that can undergo pathological fibrosis in response to injury [69]. Extraembryonic mesoderm, beyond but still continuous with the lateral plate, also may have pericytogenic potential for the vascularized extraembryonic membranes [70].

\section{Implications for pathophysiology}

Moya-moya disease (MMD) associates bilateral stenosis of the internal carotid or anterior/middle cerebral arteries, often at the level of the circle of Willis, and a profusion of telangiectatic blood vessels in a stereotyped distribution, allowing some bypassing of the stenotic area. The fact that MMD is restricted to this particular segment of the cephalic arteries, and that it has been associated with neurocristopathies, led to the hypothesis that a somatic mutation may manifest in the NCC pericytic component derived from descendents of a cell fate-mapped to the mid-rhombencephalic neural folds [71]. However, although the phenotype is localized, susceptibility can be dominantly inherited, although at low penetrance. Eastern Asian MMD is associated with a founder variation in the RNF213 gene, encoding a ring-finger AAA-type ATPase with E3 ubiquitin ligase activity[72]. A wide variety of mutations in this gene are not only associated with MMD in other ethnic populations but with intracranial aneurysm in some [73]. Unlike the ectopic but localized angiogenesis of MMD, intracranial aneuryms show thinned SMC and elastic lamina within the arterial walls at the sites of dilation, without auxiliary vessel growth. Although its role in preventing aberrant angiogenesis, particularly in the head, appears certain from knockdown studies in zebrafish [72], it is unclear how the ubiquitous expression of RNF213 translates into such a site-specific phenotype, or in which cell lineage (endothelial , NCC-pericytic, mesodermal-pericytic, or all of the above). Fate-mapping in conditional animal models could address these questions.

Pericytes of the microvasculature feeding the head and neck endocrine (pituitary, pineal, thyroid, parathyroid and ultimobranchial, for lower vertebrates) and exocrine (salivary, sweat, sebaceous, lachrymal) glands are also derived from NCC. While they are identifiably perivascular by position and alpha-SMA expression in the posterior pituitary gland, additional mesenchymal, non-endocrine NCC derivatives are present around and throughout the anterior hypophysis [74-76]. All of these cells, in the rat, appear to be nestin-immunoreactive [77], while a subpopulation of the anterior pituitary also expresses fibrillary collagen mRNAs and desmin, non-exclusive markers of pericytes [78]. Experimental removal of the neural folds leads to a malformed pituitary gland in chick. It is unclear if the NCC act on the developing pituitary gland through their role as pericytes in stabilizing the meningeal and glandular capillaries, or if there is a more direct trophic effect on neuroendocrine targets. Like the retinal primordia, salivary and lachrymal glands, and the entire telencephalon, both Rathke's pouch and the infundibulum of the diencephalic floor form initially, but are not maintained and undergo apoptosis in the absence of sufficient NCC [75].

Thymic development is likewise aborted when NCC are experimentally removed [79]. In conjunction with malformations of the cardiac outflow tract, the effects of NCC ablation correlate with their normal differentiation into thymic vascular pericytes $[36,80]$, later mediators of CD4+ T-cell emigration into the 
bloodstream [81]. The association of effects on thymus and cardiac outflow tract development implicates NCC indirectly in the pathophysiology of DiGeorge syndrome [82].

We and others have observed the presence of pigmented melanocytes in a pericytic position surrounding capillaries in the brain meninges and the pituitary of both rats and mice [83], and in the tunica media of NCC-supported blood vessels immediately afferent and efferent to the heart [55]. In the latter situation, melanocyte precursors carrying a stabilized, overactive form of a downstream effector of Wnt signaling were fate-mapped in transgenic mice. Bipotent cells that could differentiate into either melanocytes or SMC, even though a minority among the SMC population of the embryonic arterial shunt called the ductus arteriosus (DA), leaned toward more melanocyte differentiation with Wnt signaling. By so doing, they thereby deprived this vital blood vessel of sufficient SMC constriction to be able to effect its necessary closure after birth. In humans, patent DA is a life-threatening consequence of prematurity at birth, as oxygenated, high pressure blood is diverted from the aorta back into the left pulmonary artery and thereby into the lungs. A properly closed DA ultimately undergoes physiological fibrosis to evolve into the ligamentum arteriosum; untreated, patent DA can lead to congestive heart failure.

Clonal cultures of pigmented, differentiated avian melanocytes have been shown to retain the possibility of either self-renewing or redifferentiating into cells expressing morphological and molecular characteristics of either peripheral glia or pericytes in vitro, even when the original cells were derived from trunk levels [84]. All melanocytes are derived from NCC, in common with some pericytes. Their localization within blood vessels of murine meninges [85] and the heart [86] in sites shown by chick-quail chimeras to harbor NCC may reflect either a normal but as-yet unidentified secretory function of pigment cells, or simply a sensitized response to signals deployed for pericytic recruitment and vascular stabilization. However, leptomeningeal melanocytosis is a hallmark of lethal neurological symptoms in the rare disease known as giant congenital melanocytic nevus [87].

Our group has recently observed (but not yet published at the time of going to press) that in murine models of melanocytosis devoid of cancer, ectopic melanocytes are also found among the pericytes of capillary beds of the spleen, lymph nodes, gums, adrenal cortex and both male and female genital organs. Evidence that vascular pericytes and SMC of mammalian testes can, remarkably, give rise to testosterone-secreting Leydig cells was acquired through a combination of immunohistochemical and proliferation markers including but not restricted to a neurofilament, GFAP, nestin, NG2, PDGFRß. However, fate-mapping is still needed to determine the embryonic origins of these pericytes [88].

While there has been no suggestion from quail-chick chimeras of a NCC origin for these testicular cells, there are differences occasionally observed among distinct vertebrate species or classes. Notable examples are the numerous NCC identified within murine bone marrow stroma [89] and the dental pulp [90], both niches for multipotent stem cell maintenance into adulthood. In any case, pericytic misdifferentiation may play an unexpected role in male infertility, or placental vascular defects [91, 92].

A number of groups have recently turned their efforts to cultivating human pericytes from different sources, either using direct isolation from different tissue sources [93] or in differentiation from stem cell populations of distinct origins. The studies often recombine these cell sources with endothelial cells in order to understand processes of angiogenesis, in effect creating inter-individual chimeric tissues in vitro 
bioRxiv preprint first posted online Jun. 14, 2017; doi: http://dx.doi.org/10.1101/149922. The copyright holder for this preprint (which was not peer-reviewed) is the author/funder. It is made available under a CC-BY-NC-ND 4.0 International license.

[94], or inter-species chimeras in vivo with human-rodent xenografts [95]. Thus, the techniques of experimental embryology appear to be as relevant as ever to understanding pericyte function and their regulation of processes relevant to human health. 


\section{Figure 1:}

A. Drawing of a cross-section through the primitive streak of a vertebrate gastrula, highlighting contiguous populations of the three definitive germ layers (ectoderm, mesoderm and endoderm). These will each give rise to subpopulations with distinct potentials for cellular progeny by the neurula stage. $\mathbf{B}$. Drawing of a cross-section through an idealized vertebrate neurula. The neuroepithelium has invaginated to detach from the ectoderm, in blue, and the neural crest cell population has been specified at their interface and begin to undergo an epithelio-mesenchymal transition (EMT) to migrate initially between the somite and the neural tube. This first ingression of cells is followed by streams migrating through mesodermal cell compartments, particularly the ventral somite as it also undergoes EMT to become the sclerotome. Both neural crest and sclerotome are sources of pericytes. Finally, the splanchnic mesoderm, the ventral compartment of the lateral mesoderm, is the source of both epicardial and other mesothelial cells which will provide the pericytes of heart and internal organs derived from the endoderm. C. Example of a homotopic graft of quail neural crest into a chicken host.

Immunohistochemistry against a quail antigen (dark blue nuclei, arrows) highlights the presence of quailderived pericytes among the alpha smooth muscle actin-expressing cells (brown) of a forebrain capillary. Arrowheads indicate unlabeled endothelial cells in close apposition. Photograph courtesy of the author.
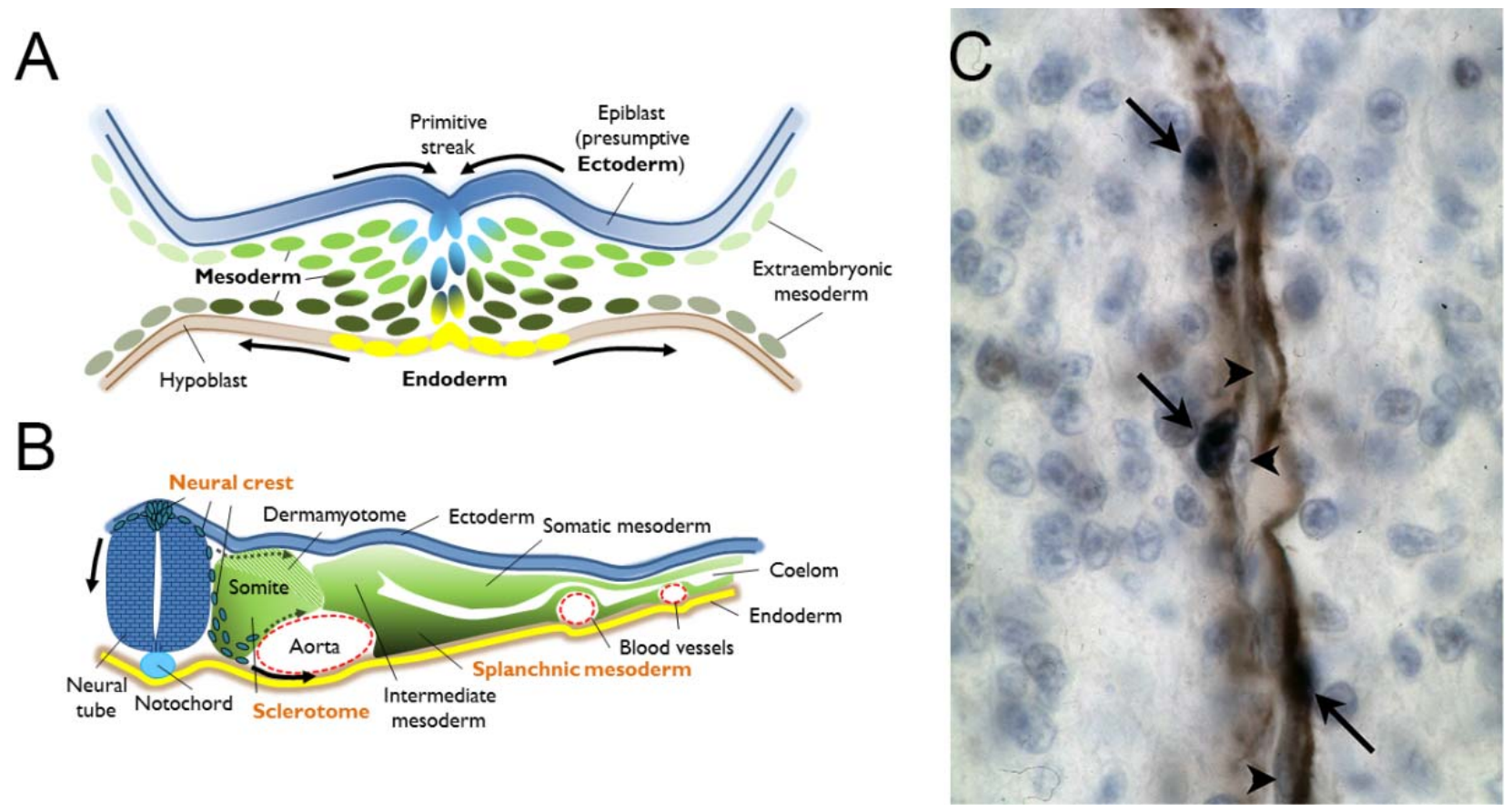


\section{Bibliography}

1. Kretzschmar K, Watt FM (2012) Lineage tracing. Cell 148:33-45. doi: 10.1016/j.cell.2012.01.002

2. Rouget $C$ (1873) Mémoire sur le dévéloppement, la structure et les proprieties physiologiques des capillaires sanguins et lymphatiques. Arch Physiol Norm Path 5:603-672.

3. Doherty MJ, Canfield AE (1999) Gene expression during vascular pericyte differentiation. Crit Rev Eukaryot Gene Expr 9:1-17.

4. Saint-Geniez M, D'Amore P a. (2004) Development and pathology of the hyaloid, choroidal and retinal vasculature. Int J Dev Biol 48:1045-1058. doi: 10.1387/ijdb.041895ms

5. Guillemin GJ, Brew BJ (2004) Microglia, macrophages, perivascular macrophages, and pericytes: a review of function and identification. J Leukoc Biol 75:388-397. doi: 10.1189/jlb.0303114

6. Thomas WE (1999) Brain macrophages: on the role of pericytes and perivascular cells. Brain Res Brain Res Rev 31:42-57.

7. Armulik A, Genové G, Betsholtz C (2011) Pericytes: Developmental, Physiological, and Pathological Perspectives, Problems, and Promises. Dev Cell 21:193-215. doi: 10.1016/j.devcel.2011.07.001

8. Lund TC, Patrinostro X, Kramer AC, et al (2014) sdf1 Expression Reveals a Source of PerivascularDerived Mesenchymal Stem Cells in Zebrafish. Stem Cells 32:2767-79. doi: 10.1002/stem.1758

9. He L, Vanlandewijck M, Raschperger E, et al (2016) Analysis of the brain mural cell transcriptome. Sci Rep 6:35108. doi: 10.1038/srep35108

10. Le Douarin N (1969) Particularités du noyau interphasique chez la Caille japonaise (Coturnix coturnix japonica). Utilisation de ces particularités comme "marquage biologique" dans les recherches sur les interactions tissulaires et les migrations cellulaires au cours de l'ont. Bull Biol Fr Belg 103:435-452.

11. Le Douarin N, Dieterlen-Lievre F, Creuzet S, Teillet M-A (2008) Quail - Chick Transplantations. Methods Cell Biol 87:19-58. doi: 10.1016/S0091-679X(08)00202-1

12. Schneider RA, Helms JA (2003) The cellular and molecular origins of beak morphology. Science (80- ) 299:565-568.

13. Fontaine-Pérus J, Chéraud Y (2005) Mouse-chick neural chimeras. Int J Dev Biol 49:349-53. doi: 10.1387/ijdb.041943jf

14. Le Douarin NM, Couly G, Creuzet SE (2012) The neural crest is a powerful regulator of pre-otic brain development. Dev Biol 1-9. doi: 10.1016/j.ydbio.2012.01.007

15. Eichmann A, Marcelle C, Breant C, Le Douarin NM (1993) Two molecules related to the VEGF receptor are expressed in early endothelial cells during avian embryonic development. Mech Dev 42:33-48.

16. Darland DC, Massingham L, Smith SR, et al (2003) Pericyte production of cell-associated VEGF is differentiation- dependent and is associated with endothelial survival. Dev Biol 264:275-288. doi: 10.1016/S0012-1606(03)00492-5 
17. Benjamin LE, Golijanin D, Itin A, et al (1999) Selective ablation of immature blood vessels in established human tumors follows vascular endothelial growth factor withdrawal. J Clin Invest 103:159-165.

18. Greenberg JI, Shields DJ, Barillas SG, et al (2008) A role for VEGF as a negative regulator of pericyte function and vessel maturation. Nature 456:809-13.

19. Couly GF, Coltey PM, Le Douarin NM (1992) The developmental fate of the cephalic mesoderm in quail-chick chimeras. Development 114:1-15.

20. Couly G, Coltey P, Eichmann A, Le Douarin NM (1995) The angiogenic potentials of the cephalic mesoderm and the origin of brain and head blood vessels. Mech Dev 53:97-112.

21. Benjamin LE, Hemo I, Keshet E (1998) A plasticity window for blood vessel remodelling is defined by pericyte coverage of the preformed endothelial network and is regulated by PDGF-B and VEGF. Cell 1598:1591-1598.

22. Péault B, Thiery J-P, Le Douarin NM (1983) A surface marker for the hemopoietic and endothelial cell lineages in the quail species defined by a monoclonal antibody. Proc Natl Acad Sci U S A 80:2976-2980.

23. Pardanaud L, Altmann C, Kitos P, et al (1987) Vasculogenesis in the early quail blastodisc as studied with a monoclonal antibody recognizing endothelial cells. Development 100:339-349.

24. Othman-Hassan K, Patel K, Papoutsi M, et al (2001) Arterial identity of endothelial cells is controlled by local cues. Dev Biol 237:398-409. doi: 10.1006/dbio.2001.0383

25. Hatzopoulos AK, Folkman J, Vasile E, et al (1998) Isolation and characterization of endothelial progenitor cells from mouse embryos. Development 125:1457-1468.

26. Jiang $X$, Rowitch $\mathrm{DH}$, Soriano $\mathrm{P}$, et al (2000) Fate of the mammalian cardiac neural crest. Development 127:1607-1616.

27. Sato $Y$, Sato $Y$, Kasai T, et al (2007) Stable integration and conditional expression of electroporated transgenes in chicken embryos. Dev Biol 305:616-24. doi: 10.1016/j.ydbio.2007.01.043

28. Yokota Y, Saito D, Tadokoro R, Takahashi Y (2011) Genomically integrated transgenes are stably and conditionally expressed in neural crest cell-specific lineages. Dev Biol 353:382-95. doi: 10.1016/j.ydbio.2011.02.001

29. Lopes M, Goupille O, Cloment CS, et al (2011) Msx genes define a population of mural cell precursors required for head blood vessel maturation. Development 138:3055-3066. doi: $10.1242 /$ dev.063214

30. Kisanuki YY, Hammer RE, Miyazaki J, et al (2001) Tie2-Cre transgenic mice: a new model for endothelial cell-lineage analysis in vivo. Dev Biol 230:230-42. doi: 10.1006/dbio.2000.0106

31. Fouquet B, Weinstein BM, Serluca FC, Fishman MC (1997) Vessel patterning in the embryo of the zebrafish: guidance by notochord. Dev Biol 183:37-48.

32. Lawson ND, Vogel AM, Weinstein BM (2002) sonic hedgehog and vascular endothelial growth 
factor act upstream of the Notch pathway during arterial endothelial differentiation. Dev Cell 3:127-36.

33. Dufourcq P, Couffinhal T, Ezan J, et al (2002) FrzA, a Secreted Frizzled Related Protein, Induced Angiogenic Response. Circulation 106:3097-3103. doi: 10.1161/01.CIR.0000039342.85015.5C

34. Le Douarin N, Kalcheim C (1999) The Neural Crest, 2nd ed. Cambridge University Press, Cambridge, U.K.

35. Pearse AG, Polak JM, Rost FW, et al (1973) Demonstration of the neural crest origin of type I (APUD) cells in the avian carotid body, using a cytochemical marker system. Histochemie 34:191203.

36. Le Lievre CS, Le Douarin NM (1975) Mesenchymal derivatives of the neural crest: analysis of chimaeric quail and chick embryos. J Embryol Exp Morphol 34:125-154.

37. Le Douarin N, Fontaine J, Le Lievre C (1974) New studies on the neural crest origin of the avian ultimobranchial glandular cells--interspecific combinations and cytochemical characterization of $C$ cells based on the uptake of biogenic amine precursors. Histochemistry 38:297-305.

38. Polak JM, Pearse AG, Le Lievre C, et al (1974) Immunocytochemical confirmation of the neural crest origin of avian calcitonin-producing cells. Histochemistry 40:209-214.

39. Johnston MC, Noden DM, Hazelton RD, et al (1979) Origins of avian ocular and periocular tissues. Exp Eye Res 29:27-43. doi: 10.1016/0014-4835(79)90164-7

40. Noden DM (1983) The role of the neural crest in patterning of avian cranial skeletal, connective, and muscle tissues. Dev Biol 96:144-165.

41. Couly GF, Coltey PM, Le Douarin NM (1993) The triple origin of skull in higher vertebrates: a study in quail-chick chimeras. Development 117:409-429.

42. Couly G, Grapin-Botton A, Coltey P, Le Douarin NM (1996) The regeneration of the cephalic neural crest, a problem revisited: the regenerating cells originate from the contralateral or from the anterior and posterior neural fold. Development 122:3393-3407.

43. Köntges G, Lumsden A (1996) Rhombencephalic neural crest segmentation is preserved throughout craniofacial ontogeny. Development 122:3229-3242.

44. Etchevers HC, Couly G, Vincent C, Le Douarin NM (1999) Anterior cephalic neural crest is required for forebrain viability. Development 126:3533-3543.

45. Creuzet SE (2009) Regulation of pre-otic brain development by the cephalic neural crest. Proc Natl Acad Sci U S A 106:15774-15779. doi: 10.1073/pnas.0906072106

46. Nolan K, Thompson TB (2014) The DAN family: Modulators of TGF-B signaling and beyond. Protein Sci 23:999-1012. doi: 10.1002/pro.2485

47. Aguiar DP, Sghari S, Creuzet S (2014) The facial neural crest controls fore- and midbrain patterning by regulating Foxg1 expression through Smad1 activity. Development 141:2494-505. doi: $10.1242 /$ dev.101790 
48. Creuzet S, Schuler B, Couly G, Le Douarin NM (2004) Reciprocal relationships between Fgf8 and neural crest cells in facial and forebrain development. Proc Natl Acad Sci U S A 101:4843-7. doi: 10.1073/pnas.0400869101

49. Johnston MC (1966) A radioautographic study of the migration and fate of cranial neural crest cells in the chick embryo. Anat Rec 156:143-55. doi: 10.1002/ar.1091560204

50. Bergwerff M, Verberne ME, DeRuiter MC, et al (1998) Neural crest cell contribution to the developing circulatory system: implications for vascular morphology? Circ Res 82:221-31.

51. Nishibatake M, Kirby ML, Van Mierop LH (1987) Pathogenesis of persistent truncus arteriosus and dextroposed aorta in the chick embryo after neural crest ablation. 75:255-264.

52. Waldo K, Miyagawa-Tomita S, Kumiski D, Kirby ML (1998) Cardiac neural crest cells provide new insight into septation of the cardiac outflow tract: aortic sac to ventricular septal closure. 196:129-144.

53. Etchevers HC, Vincent C, Le Douarin NM, Couly GF (2001) The cephalic neural crest provides pericytes and smooth muscle cells to all blood vessels of the face and forebrain. Development 128:1059-68.

54. Yablonka-Reuveni Z, Schwartz SM, Christ B (1995) Development of chicken aortic smooth muscle: expression of cytoskeletal and basement membrane proteins defines two distinct cell phenotypes emerging from a common lineage. Cell Mol Biol Res 41:241-9.

55. Yajima I, Colombo S, Puig I, et al (2013) A subpopulation of smooth muscle cells, derived from melanocyte-competent precursors, prevents patent ductus arteriosus. PLoS One 8:e53183. doi: 10.1371/journal.pone.0053183

56. Gittenberger-de Groot AC, Vrancken Peeters MP, Mentink MM, et al (1998) Epicardium-derived cells contribute a novel population to the myocardial wall and the atrioventricular cushions. Circ Res 82:1043-1052. doi: 10.1161/01.RES.82.10.1043

57. Ando K, Fukuhara S, Izumi N, et al (2016) Clarification of mural cell coverage of vascular endothelial cells by live imaging of zebrafish. Development 1328-1339. doi: 10.1242/dev.132654

58. Wang Y, Pan L, Moens CB, Appel B (2014) Notch3 establishes brain vascular integrity by regulating pericyte number. Development 141:307-317. doi: 10.1242/dev.096107

59. Mikawa T, Gourdie RG (1996) Pericardial mesoderm generates a population of coronary smooth muscle cells migrating into the heart along with ingrowth of the epicardial organ. Dev Biol 174:221-232. doi: 10.1006/dbio.1996.0068

60. Dettman RW, Denetclaw W, Ordahl CP, Bristow J (1998) Common epicardial origin of coronary vascular smooth muscle, perivascular fibroblasts, and intermyocardial fibroblasts in the avian heart. Dev Biol 193:169-81. doi: 10.1006/dbio.1997.8801

61. Volz KS, Jacobs AH, Chen HI, et al (2015) Pericytes are progenitors for coronary artery smooth muscle. Elife 4:7250-7257. doi: 10.7554/eLife.10036

62. van den Berg G, Abu-Issa R, de Boer B a, et al (2009) A caudal proliferating growth center contributes to both poles of the forming heart tube. Circ Res 104:179-88. doi: 


\subsection{1/CIRCRESAHA.108.185843}

63. Laforest B, Bertrand N, Zaffran S (2014) Anterior Hox Genes in Cardiac Development and Great Artery Patterning. J Cardiovasc Dev Dis 1:3-13. doi: 10.3390/jcdd1010003

64. Schlueter J, Brand T (2013) Subpopulation of proepicardial cells is derived from the somatic mesoderm in the chick embryo. Circ Res 113:1128-1137. doi: 10.1161/CIRCRESAHA.113.301347

65. Peng $\mathrm{T}$, Tian $\mathrm{Y}$, Boogerd $\mathrm{CJ}$, et al (2013) Coordination of heart and lung co-development by a multipotent cardiopulmonary progenitor. Nature 4:3-7. doi: 10.1038/nature12358

66. Wilm B, Ipenberg A, Hastie ND, et al (2005) The serosal mesothelium is a major source of smooth muscle cells of the gut vasculature. Development 132:5317-5328. doi: 10.1242/dev.02141

67. Pouget $\mathrm{C}$, Pottin K, Jaffredo T, et al (2008) Sclerotomal origin of vascular smooth muscle cells and pericytes in the embryo. Dev Biol 315:437-447. doi: 10.1016/j.ydbio.2007.12.045

68. Wiegreffe C, Christ B, Huang R, Scaal M (2009) Remodeling of aortic smooth muscle during avian embryonic development. Dev Dyn 238:624-631.

69. Humphreys BD, Lin S-L, Kobayashi A, et al (2010) Fate tracing reveals the pericyte and not epithelial origin of myofibroblasts in kidney fibrosis. Am J Pathol 176:85-97. doi: 10.2353/ajpath.2010.090517

70. Kurz H, Fehr J, Nitschke R, Burkhardt H (2008) Pericytes in the mature chorioallantoic membrane capillary plexus contain desmin and $\alpha$-smooth muscle actin: Relevance for non-sprouting angiogenesis. Histochem Cell Biol 130:1027-1040. doi: 10.1007/s00418-008-0478-8

71. Etchevers H (2003) Vasculo-and angio-genesis in the head and neck. Riv di Neuroradiol 16:735738.

72. Liu W, Morito D, Takashima S, et al (2011) Identification of RNF213 as a susceptibility gene for moyamoya disease and its possible role in vascular development. PLoS One. doi: 10.1371/journal.pone.0022542

73. Zhou S, Ambalavanan A, Rochefort D, et al (2016) RNF213 Is Associated with Intracranial Aneurysms in the French-Canadian Population. Am J Hum Genet. doi: 10.1016/j.ajhg.2016.09.001

74. Le Lièvre CS, Le Douarin NM (1975) Mesenchymal derivatives of the neural crest: analysis of chimaeric quail and chick embryos. J Embryol Exp Morphol 34:125-154.

75. Etchevers H, Couly G, Vincent C, Le Douarin N (1999) Anterior cephalic neural crest is required for forebrain viability. Development 126:3533-3543.

76. Etchevers HC, Vincent C, Couly G (2001) Neural crest and pituitary development. In: Rappaport R, Amselem S (eds) Hypothal. Dev. Genet. Clin. Asp. Karger Publishers, Basel, p 190

77. Krylyshkina O, Chen J, Mebis L, et al (2005) Nestin-immunoreactive cells in rat pituitary are neither hormonal nor typical folliculo-stellate cells. Endocrinology 146:2376-2387. doi: 10.1210/en.2004-1209

78. Fujiwara K, Jindatip D, Kikuchi M (2010) In situ hybridization reveals that type I and III collagens 
are produced by pericytes in the anterior pituitary gland of rats. Cell Tissue Res 491-495. doi: 10.1007/s00441-010-1078-1

79. Bockman DE, Kirby ML (1984) Dependence of thymus development on derivatives of the neural crest. Science (80- ) 223:498-500.

80. Müller SM, Stolt CC, Terszowski G, et al (2008) Neural crest origin of perivascular mesenchyme in the adult thymus. J Immunol 180:5344-51.

81. Zachariah MA, Cyster JG (2010) Neural Crest-Derived Pericytes Promote Egress of Mature Thymocytes at the Corticomedullary Junction. Science (80- ) 328:1129-1135. doi: $10.1126 /$ science. 1188222

82. Hutson MR, Kirby ML (2003) Neural crest and cardiovascular development: a 20-year perspective. 69:2-13.

83. Fetissov SO, Barcza M a, Meguid MM, Oler A (1999) Hypophysial and meningeal melanocytes in the Zucker rat. Pigment Cell Res 12:323-30.

84. Real C, Glavieux-Pardanaud C, Le Douarin NM, Dupin E (2006) Clonally cultured differentiated pigment cells can dedifferentiate and generate multipotent progenitors with self-renewing potential. Dev Biol 300:656-69. doi: 10.1016/j.ydbio.2006.09.032

85. Gudjohnsen SAH, Atacho DAM, Gesbert F, et al (2015) Meningeal Melanocytes in the Mouse: Distribution and Dependence on Mitf. Front Neuroanat 9:149. doi: 10.3389/fnana.2015.00149

86. Brito FC, Kos L (2008) Timeline and distribution of melanocyte precursors in the mouse heart. Pigment Cell Melanoma Res 21:464-70. doi: 10.1111/j.1755-148X.2008.00459.x

87. Reyes-Múgica M, Beckwith M, Etchevers HC (2012) Etiology of congenital melanocytic nevi and related conditions. In: Nevogenes. (Practical Clin. Med. Ser. Med. p sous presse

88. Davidoff MS, Middendorff R, Enikolopov G, et al (2004) Progenitor cells of the testosteroneproducing Leydig cells revealed. J Cell Biol 167:935-44. doi: 10.1083/jcb.200409107

89. Nagoshi N, Shibata S, Kubota Y, et al (2008) Ontogeny and Multipotency of Neural Crest-Derived Stem Cells in Mouse Bone Marrow, Dorsal Root Ganglia, and Whisker Pad. Cell Stem Cell 2:392403. doi: 10.1016/j.stem.2008.03.005

90. Chai $Y$, Jiang $X$, Ito $Y$, et al (2000) Fate of the mammalian cranial neural crest during tooth and mandibular morphogenesis. Development 127:1671-9.

91. Hellström M, Gerhardt H, Kalén M, et al (2001) Lack of pericytes leads to endothelial hyperplasia and abnormal vascular morphogenesis. J Cell Biol 153:543-53.

92. Khan JA, Mendelson A, Kunisaki Y, et al (2016) Fetal liver hematopoietic stem cell niches associate with portal vessels. Science (80- ) 351:176-180. doi: 10.1126/science.aad0084

93. Herrmann M, Bara JJ, Sprecher CM, et al (2016) Pericyte plasticity - comparative investigation of the angiogenic and multilineage potential of pericytes from different human tissues. Eur Cell Mater 31:236-49. 
bioRxiv preprint first posted online Jun. 14, 2017; doi: http://dx.doi.org/10.1101/149922. The copyright holder for this preprint (which was not peer-reviewed) is the author/funder. It is made available under a CC-BY-NC-ND 4.0 International license.

94. Bargehr J, Low L, Cheung C, et al (2016) Embryological Origin of Human Smooth Muscle Cells Influences Their Ability to Support Endothelial Network Formation. Stem Cells Transl Med 5:946959. doi: 10.5966/sctm.2015-0282

95. Steinbach SK, Husain M (2016) Vascular smooth muscle cell differentiation from human stem/progenitor cells. Methods 101:85-92. doi: 10.1016/j.ymeth.2015.12.004 